\title{
Inmunorreactividad de la proteína p53 en lesiones premalignas y malignas del cérvix uterino
}

\author{
Alirio López*, Lesly Cerrato*, Reynaldo Castro*, \\ Belinda Hasbun de Cadillo**, Jorge Carrasco***
}

\section{RESUMEN}

Objetivo: Determinar la expresión p53 en las lesiones premalignas y malignas del cérvix en las pacientes de la consulta externa del servicio de Ginecología del Hospital Materno Infantil durante el período de julio de 2008 a diciembre de 2009.

Material y métodos: Se realizó un estudio de tipo descriptivo transversal. Estudiándose una muestra de 90 pacientes de un universo de 209 pacientes. Las pacientes se caracterizaron según sus factores de riesgo además se tomó biopsia por colposcopia y/o conización a las pacientes con sospecha clínica de lesión premaligna o maligna del cérvix uterino. Las biopsias fueron incluidas en bloques parafina para la tinción con Hematoxilina - Eosina, y luego a la recuperación del antígeno p53, utilizando un anticuerpo policlonal mediante la técnica de inmunoperoxidasa, para su posterior análisis estadístico.

Resultados: La edad media fue de 40.9 años (rango 18-105 años). La escolaridad media fue de 6.8 años, con rango de 1 a 15 años. El 50\% (45) de las pacientes refirió haber tenido solo una pareja sexual. El $92.2 \%$ (83) de las biopsias fueron en sacabocado y $7.8 \%$ (7) fueron conizaciones. De los resultados de biopsia el 10\% (9 casos) fueron carcinoma de células escamosas invasor, lesión de intraepitelial escamosa de alto grado - NIC III 23.3\% (21 casos), NIC II 23.3\% (14 casos), NIC I $33.3 \%$ (30 casos) y el 16 casos (17.8\%) correspondió a otras lesiones donde se incluyen endocervicitis crónica, pólipo endocervical, negativo por malignidad, cambios reparativos atípicos. Se realizó identificación de la proteína p53, en 73 casos clasificados previamente como lesión premaligna y/o maligna del cérvix, obteniendo los siguientes resultados; de los carcinomas de células escamosas 6 de 9 casos $(66.67 \%)$ presentaron positividad nuclear, NIC III $12 / 21$ casos positivos $(57.14 \%)$, NIC II $3 / 14$ casos positivos (21.42\%), NICI 12/30 casos positivos (40\%).

Palabras clave: Proteína p53, Carcinoma de células escamosas, neoplasia cervical intraepitelial.

${ }^{*}$ Residentes 4to. Año Anatomia Patologica UNAH

* Coordinadora de docencia Anatomia Patologica UNAH

*Profesor titular Microbilogia UNAH 


\section{ABSTRACT}

Objective: To determine the expression p53 in malign and pre-malignlesions of the cervix in the patients of the Consulta Externa of the Service of Gynecology of the Hospital Materno Infantil during the period of July 2008 to December 2009.

Material and method: A study of cross-sectional descriptive type. Studying a sample of 90 patients of a Universe of 209. The patients were characterized according to their risk factors, in addition biopsy by colposcopy and/or conizacion to the patients with clinical suspicion of malign or pre-malign injury of uterine cervix were made. The biopsies were including in paraffin blocks for the staining with Hematoxilina - Eosin and posterior the recovery of the antigen p53, using a policlonal antibody by means of the inmunoperoxidase technique of, for its later statistical analysis.

Results: The mean age was of 40,9 years (rank 18-105 years). The average schooling was of 6,8 years, with rank of 1 to 15 years. $50 \%$ (45) of the patients referred to have had single a sexual pair. The $92,2 \%(83)$ of the biopsies were in punch and 7,8\% (7) were cones. Of the biopsy results 10\% (9 cases) were invasive carcinoma of squamous cells, $23,3 \%$ (21 cases) High degree intraepithelial lesions CIN III, CIN II 23,3\% (14 cases), 33,3\% (30 cases) where CIN I and 16 cases $(17,8 \%)$ corresponded to other injuries where chronic endocervicitis, endocervical, polyp by atypical reparative changes were included. The identification of the protein p53, was made in 73 cases previously classified as malign or pre-malign lesions of the cervix, obtaining the following results; 6 of 9 cases of of carcinomas of squamous cells $(66,67 \%)$ presented/displayed nuclear positividad, NIC III 12/21 positive cases (57,14\%), NIC II $3 / 14$ positive cases $(21,42 \%)$, NIC I $12 / 30$ positive cases $(40 \%)$.

Key words: protein p53, squalors carcinoma cell, cervical intraepithelial neoplasia. 


\section{INTRODUCCIÓN}

El gen supresor tumoral p53 se detecta de forma normal en el núcleo de todas las células del organismo, en situaciones de estrés celular, particularmente cuando se produce daño al ADN. El gen p53 contrarresta la progresión del ciclo celular, permitiendo la reparación del ADN o apoptosis .

En el cáncer cuando existen mutación del gen p53, se desencadena una proliferación celular descontrolada con reparación ineficiente del ADN e inestabilidad del genoma. Ante este daño los niveles séricos del anticuerpo anti p53 se hacen detectables.

Se estima que la mutación del gen p53 es el evento genético más frecuente en los cánceres humanos y está presente en más del $50 \%$ de los casos, por lo que, en el carcinoma epidermoide del cérvix, algunos factores de riesgo como ser el virus del papiloma humano (tipo 16,18) reportado en el $95 \%$ de los casos, múltiples parejas sexuales, anticonceptivos orales e historia familiar de carcinoma epidermoide, desencadenan inestabilidad en el ciclo celular y genes de supresión tumoral entre ellosp53.

Esta neoplasia ocupa el segundo lugar en mujeres en todo el mundo, reportándose anualmente 500,000 nuevos casos con alta mortalidad en mujeres de países en desarrollo. En Honduras, es el cáncer más frecuente y representa la primera causa de muerte en mujeres en edad fértil.

\section{MATERIAL Y MÉTODOS}

Se realizó un estudio descriptivo transversal en el área de consulta externa del servicio de Ginecología del Hospital Materno Infantil durante el periodo de julio de 2008 a diciembre de 2009. El universo lo constituyó 209 pacientes, y la muestra fue de 90 pacientes con lesión premaligna o maligna del cérvix. A las pacientes se les explicó de forma clara y precisa los objetivos del estudio. Se recolectó la información en un instrumento previamente validado por el comité de Ética de los postgrados de medicina, en el cual constó de 14 preguntas cerradas, donde se incluyeron datos generales (edad, procedencia, ocupación, estado civil, nivel de escolaridad, ingreso familiar, tipo de vivienda), antecedentes personales (infecciones de transmisión sexual, tipo de tratamiento recibido, número de parejas sexuales), tipo y resultado de biopsia, tipo de lesión premaligna o maligna y reactividad para p53. La participación fue voluntaria y solo se considerarán reclutadas para el estudio las 
mujeres (o sus representantes legales en caso de ser menores de edad) que voluntariamente firmaron el consentimiento informado.

Una vez aplicada la encuesta, se recolectó biopsia colposcopica y/o conizacion, las cuales se fijaron en formalina bufferada al 10\%, se realizó coloraciones de rutina Hematoxilina y Eosina y técnicas de inmunoperoxidasa para determinar las características biológicas de la neoplasia (positividad o negatividad por malignidad, tipo y grado histológico de la lesión, profundidad de la invasión e infiltración vascular y glandular positividad del anticuerpo p53.).

Con respecto a la técnica de inmunoperoxisada para la obtención y marcaje del anticuerpo p53, consta de cinco pasos, como se describe:

A. Cortes: Se realizaron cortes de tejido incluido en parafina, se procedió a desparafinar el de tejido en xileno, dos veces durante cinco minutos cada vez, luego a hidratar con etanol absoluto dos veces durante cinco minutos, se continuó hidratando con etanol al $95 \%$, dos veces por 5 minutos cada vez, y se procedió a la lavar en PBS por 10 minutos.

B. Bloqueo: los cortes de tejido fueron bloqueados para inhibir la peróxidasa endógena con (90 ml de metanol, $5 \mathrm{ml}$ de agua destilada, $5 \mathrm{ml}$ de peróxido al 30\%), a temperatura ambiente durante 20 minutos en cámara húmeda, luego se procedió a lavar con PBS tres veces durante tres minutos cada vez, se secó el exceso, se añadieron gotas de suero de oveja diluida 1:100 al 1\% en PBS, se incubaron durante 30 minutos a temperatura ambiente.

C. Incubación se procedió a la incubación del tejido con el anticuerpo primario (anticuerpo monoclonal de conejo) en una dilución de 1:500 en PBS, se procedió a incubar a temperatura ambiente en cámara húmeda, se lavaron las laminas con PBS tres veces en tres minutos en cada ocasión.

D. Se incubaron los tejidos con anticuerpo policlonal p53 de tipo salvaje de ciclina D1 (CD1.1) ALX-8D4539-C100AXXOR en una dilución de 1:50 en PBS, a temperatura ambiente, durante 30 minutos en cámara húmeda, se lavaron las láminas cinco veces en PBS durante tres minutos en cada ocasión.

E. Revelado: se incubó con solución reveladora cinco ml de agua destilada, dos gotas de solución de peroxidasa, tres gotas de Tris Buffer, dos gotas DAB sustrato. Detener la reacción antes de los seis minutos con agua. Teñir con hematolixina de Meyer (coloración de contraste) durante cinco minutos, luego se lavó con agua. 
Luego se deshidrataron las láminas en etanol al 95\%, una vez durante tres minutos, luego con etanol absoluto tres veces durante tres minutos cada vez y xilol dos veces durante cinco minutos cada ocasión, y se procedió a montar con bálsamo de Canadá. La totalidad de las muestras fueron estudiadas por los patólogos del Hospital Escuela, y posteriormente por el patólogo asesor del proyecto de investigación en dos tiempos, y sin conocimiento previo del diagnóstico original. De existir discordancia diagnostica se recurrió a un tercer patólogo para llegar a un diagnostico consensuado. Para realizar el respectivo análisis descriptivo se tabuló los resultados con el programa estadístico Epi Info versión 3.3.6 de 2007.

\section{RESULTADOS}

Se recolectó un total de 90 biopsias de las pacientes que asistieron a la consulta externa de Ginecología del hospital Materno Infantil con sospecha clínica de lesión pre-neoplásica y neoplásica del cérvix durante el período de julio de 2008 a diciembre de 2009, las cuales tenían una media de edad de 40.9 años (rango 18-105 años) de escolaridad media de 6.8 años con un rango de 1 a 15 años y con un ingreso monetario promedio de $L 1,001.00$ a 3,000.00 (tres pacientes se negaron a proporcionar este dato).

Como parte del estudio, se determinó el número de parejas sexuales encontrando que el 50 por ciento había tenido una pareja sexual, seguido de 41.1 por ciento de pacientes con 2 a 3 parejas sexuales y solamente una paciente había tenido de 6 a 10 parejas sexuales (ver tabla $\mathrm{N}^{\circ} 1$ ).

Tabla No. 1. Número de parejas sexuales de las pacientes que asistieron a la consulta externa de julio de 2008 a diciembre 2009

\begin{tabular}{|c|c|c|}
\hline $\begin{array}{c}\text { Número de parejas } \\
\text { sexuales }\end{array}$ & Frecuencia & Porcentaje \\
\hline 1 & 45 & $50.0 \%$ \\
\hline $2-3$ & 37 & $41.1 \%$ \\
\hline $4-5$ & 7 & $7.8 \%$ \\
\hline $6-10$ & 1 & $1.1 \%$ \\
\hline Total & 90 & $100.0 \%$ \\
\hline * Departamento de Anatomía Patológica, Hospital Escuela
\end{tabular}


En este estudio, contrario a lo que se reporta en la literatura, el número de parejas sexuales no fue factor de riesgo determinante para carcinoma de cérvix porque el $57.14 \%$ de las pacientes con carcinomas referían haber tenido solo una pareja. (ver Tabla No. 2)

Tabla No. 2. Relación de carcinoma de células escamosas con número de parejas sexuales

\begin{tabular}{|c|c|c|}
\hline Número de parejas & $\begin{array}{c}\text { Carcinoma de } \\
\text { células escamosas }\end{array}$ & Porcentaje \\
\hline 1 & 4 & $47.14 \%$ \\
\hline $2-3$ & 5 & $42.85 \%$ \\
\hline $4-5$ & 0 & $0 \%$ \\
\hline $6-10$ & 0 & $0 \%$ \\
\hline $11-20$ & 0 & $0 \%$ \\
\hline$>20$ & 0 & $0 \%$ \\
\hline Total & 9 & $100.0 \%$ \\
\hline * Departamento de Anatomía Patológica, Hospital Escuela
\end{tabular}

Se estudió la sintomatología de las pacientes encontrando que la secreción vaginal fue el único signo contribuyente el cual estuvo presente en el $81.1 \%$ de todos los casos, esto es congruente con la literatura la cual reporta que las infecciones vaginales manifiestas con secreción vaginal constituyen un factor de riesgo de las lesiones pre neoplásicas y neoplásicas de cérvix.

Del total de las biopsias se recibieron un $92.2 \%$ en sacabocado ( $83 / 90$ casos) y el $7.8 \%$ restante fueron obtenidas por cono cervicales. (ver Tabla No.3) 
Tabla No. 3. Análisis del tipo de biopsia de las pacientes que asistieron a la consulta externa de julio de 2008 a diciembre 2009

\begin{tabular}{|c|c|c|}
\hline Tipo de biopsia & Frecuencia & Porcentaje \\
\hline Cono & 7 & $7.8 \%$ \\
\hline Sacabocado & 83 & $92.2 \%$ \\
\hline Total & 90 & $100.0 \%$ \\
\hline * Departamento de Anatomía Patológica, Hospital Escuela
\end{tabular}

Los resultados de las biopsias son resumidos en la Tabla 4.

Tabla No. 4. Resultados de las biopsias según clasificación de la OMS

\begin{tabular}{|c|c|c|}
\hline $\begin{array}{c}\text { Resultado de la } \\
\text { biopsia }\end{array}$ & Frecuencia & Porcentaje \\
\hline Carcinoma invasor & 9 & $10 \%$ \\
\hline NICIII & 21 & $23.3 \%$ \\
\hline CICII & 14 & $15.6 \%$ \\
\hline CICI & 30 & $33.3 \%$ \\
\hline Otro & 16 & $17.8 \%$ \\
\hline Total & 90 & $100.0 \%$ \\
\hline * Departamento de Anatomía Patológica, Hospital Escuela
\end{tabular}

Un 17.8\% que representa 16/90 casos entraron en la categoría de otros dentro de los cuales se incluyeron: endocervicitis crónica 12 casos, pólipo endocervical un caso, negativos por malignidad dos casos, cervicitis con cambios reparativos atípicos un caso. Se realizó la técnica de inmunoperoxidasa en 74/90 biopsias cervicales para determinar la inmunorreactividad del gen p53, excluyéndose los 16 casos que fueron reportados dentro del aparado de otros. Los resultados fueron positivos en el $44.5 \%$ (33/74 casos) distribuidos de la siguiente manera: $66.67 \%$ carcinoma invasor, $57.14 \%$ NIC III, 21.42\% NIC II y 40\% NIC I. La Inmunotinción fue 
restringida al epitelio como marcador de tinción nuclear, observándose que en los carcinomas in situ (NIC III) (Foto 1), la tinción fue positiva en el espesor total de epitelio (Foto 2) a diferencia de las lesiones intraepiteliales escamosas de alto y bajo grado (NIC II y NIC I) en donde la tinción fue variable tanto en las capas basal, suprabasal y media (Foto 3 ).

Se demostró una correlación positiva entre el grado de la lesión y la expresión de inmunotinción para p53 en lo que es carcinoma invasor y NIC III, no así en lo que es NIC II, esto deducimos se debe a que la sobre expresión de p53 es mayor en lesiones con una mutación más estable del gen p53 de lo que se puede encontrar en los NIC II. La expresión de p53 en las lesiones activas por VPH con cambios citopáticos (Coilocitos NIC I) explican porque la correlación es algo mayor en NIC I que en NICII (ver Tabla 5).

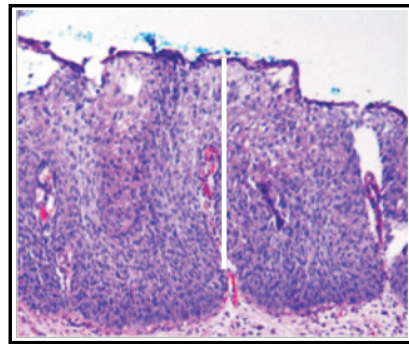

Foto 1. Lesión Intraepitelial de Alto Grado, NIC III mostrando células tumorales en todo el espesor del cérvix

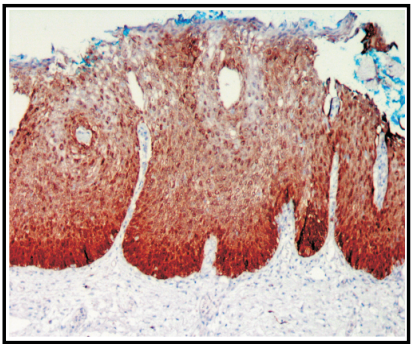

Foto 2. La lesión anterior con inmunotinción p53 positividad citoplasmática y nuclear en capas basal, media y superficial

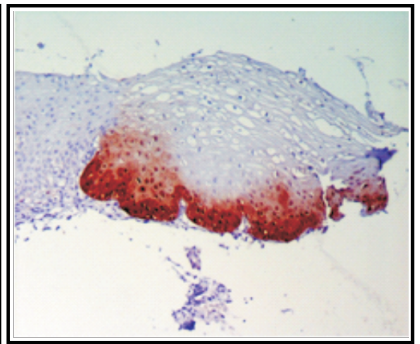

Foto 3. Lesión Intraepitelial de Bajo Grado NIC I con tinción p53 positiva en células epiteliales de la capa basal

Tabla No. 5. Correlación entre la expresión de p53 y el grado de lesión epitelial

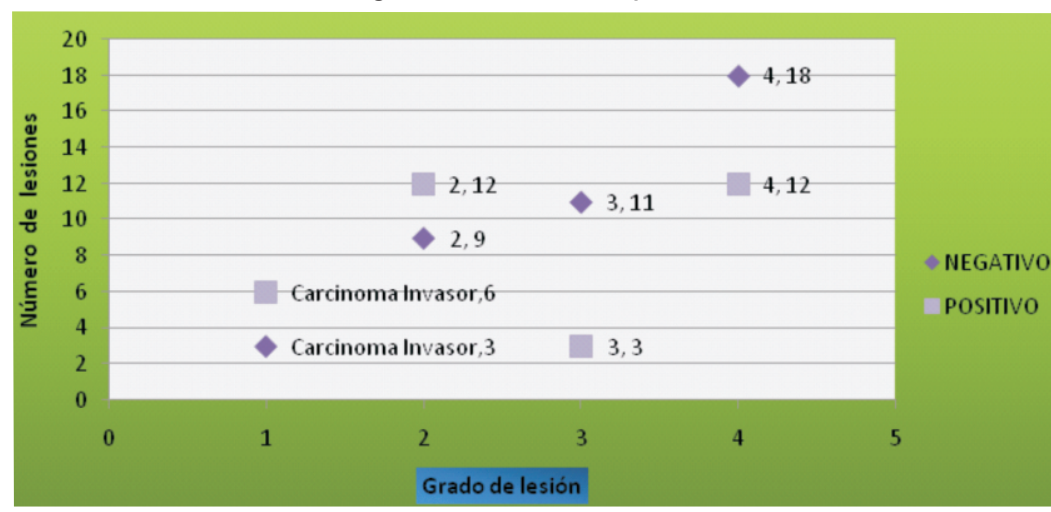

* Departamento de Anatomía Patológica, Hospital Escuela 


\section{CONCLUSIÓN}

El estudio demostró que la inmunoreactividad de p53 fue mayor en las lesiones de alto grado (NIC III) y carcinoma invasor con un 57.14 y $66.67 \%$ respectivamente, con una correlación positiva como lo apoya la literatura en donde a mayor grado de lesión tanto premaligna y maligna, mayor será la expresión de p53. La sobre expresión de p53 se observa tanto en lesiónes neoplasicas como en lesiones premalignas en la presencia del VPH por lo que es un marcador que se utiliza sobre todo para la diferenciación de lesiones escamosas displasicas y neoplasicas de las metaplasicas e hiperplasicas .

En la actualidad, a más de 30 años de estudio sobre el gen p53 se desarrollan aún nuevas terapias enfocadas en evitar la degradación de la proteína p53, ya sea bloqueando la proteína E6 del VPH o el bloqueo de otros antagonistas del gen p53 recalcando la importancia de continuar estudiando esta proteína y la importancia de demostrar su sobreexpresión en lesiones cervicales.

Con lo anterior podemos concluir que las técnicas de inmunohistoquimica son un instrumento muy útil para la detección de lesiones escamosas de alto grado del cérvix y una herramienta indispensable para el ejercicio diagnostico del residente. Se concluye además que la implementación de la técnica de inmunohistoquimica es factible en el laboratorio de histotecnologia del Departamento de Patología del Hospital Escuela con el equipo, recurso humano e infraestructura disponible actualmente.

\section{BIBLIOGRAFÍA}

Jara D; Rengifo E; Malaspina $\mathrm{M}$; et al. Detección Inmunohistoquímica de Papilomavirus Humano en Neoplasias Cervicales. Anales de la Facultad de Medicina Universidad Nacional Mayor de San Marcos. Vol. 61, №1 - 2000. pp 1025-1083.

UNAM, León [tesis en PDF]. Salinas Xiomara. Valoracion de la citologia y de la colposcopia en el diagnostico de neoplasias intraepiteliales del cuello uterino durante el periodo 2000-2003 en el heodra- leon. [Accesado el 11 de Agosto del 2006]. Disponible en: www.minsa.gob.ni/enfermeria/PDF/126.

Larizgoitia I. Diagnóstico precoz del cáncer cervical: conocimiento actual sobre viejas y nuevas tecnologías. [ Publicado en PDF ]. Noviembre 2000. [Accesado el 12 de Agosto del 2006]. Disponible en:

www.gencat.net/salut/depsan/units/aatrm/pdf/br0102es.pdf 
E: Trau Nazzal O; Reinero M; Abarzúa A; Liendo R; Palma C. Patología Preinvasora del Cervix. Revista Chilena de Ginecología y Obstetricia 2003; 68(3): 189-196. [Accesado el 10 de Agosto del 2006]. Disponible en:

www.scielo.cl/scielo.php?pid=S071775\&script=sci_arttext\&tlng=es52k.

Christopher P. Aparato Genital Femenino Cotran R; Kumar V; Collins. Patología Estructural y Funcional. 6ta Ed.McGraw-Hill Interamerican de España, S.A.U. 2000. pp 1105-1107.

UNAM, León [ Monografía en PDF ]. Membreño N; Proyecto de detección oportuna del cáncer cervical en los municipios de Catarina, san Juan de oriente y Niquinohomo Masaya, 1997 - 1998. [Accesado el 11 de Agosto del 2006]. Disponible en: www.minsa.gob.ni/enfermeria/PDF/354.PDF.

Herrera G; Camargo E; Chávez G. Lesiones preneoplásicas de cuello uterino en mujeres menores de 30 años. Ginecología y Obstetricia - Vol. 45 №1 Enero 1999 [Accesado el 10 de Agosto del 2006]. Disponible en:

http://sisbib.unmsm.edu.pe/BVRevistas/ginecologia/Vol_45N1/lesiones_ preneoplasicas.htm.

Meléndez Bardales J, Ochoa Vásquez J, Villanueva M. Investigación sobre Mortalidad. Materna y de mujeres en edad reproductiva en Honduras. 1997.

Borges M, Sanamé O, Hartmann A, Teran S. Comportamiento de las neoplasias intraepiteliales cervicales (NIC) en pacientes menores de 25 años de edad. Estudio de un año (2002). H.G:D Baracoa Guantánamo. [Accesado el 13 de Agosto del 2006]. Disponible en:

http://conganat.uninet.edu/6CVHAP/autores/trabajos/T320/index.html

UNAM, León. [tesis en PDF].Delgadillo B. P; Cáncer Cervico-Uterino en el departamento de León durante el período 1999 al 2002. [Accesado el 11 de Agosto del 2006]. www.minsa.gob.ni/enfermeria/PDF/122.pdf.

Gonzáles J, Chavez J, Hernandez D. Infección por virus del papiloma humano de alto y bajo riesgo en mujeres con nic. Características diferenciales. Revista Chilena de Ginecología y Obstetricia 2002; Vol. 70(1):11-16. [Accesado el 10 de Agosto del 2006]. Disponible en:

www.scielo.cl/scielo.php?pid=S071775262003000300001\&script=sci_ arttext\&tIng=es - 52k.

Grases, Pedro: Patología Ginecológica 1 ed, MASSON 2003, Barcelona España. pp: 116-118.

Secretaría de Salud: Manual de Normas y Procedimientos de Laboratorio de Citología Cervico-Uterino. 2003.

Nauth, H. F. Citodiagnóstico Ginecológico 1 ed, Buenos Aires 2004.

Koivusalo Riku Mialon Antoine Pitkänen Hanna Westermarck Jukka and Hietanen Sakari Activation of p53 in Cervical Cancer Cells by Human Papillomavirus E6 RNA Interference Is Transient, but Can Be Sustained by 
Inhibiting Endogenous Nuclear Export-Dependent p53 Antagonists Cancer Res December 15, 2006.

Ying Zhao Carolyn Szekely Laszlo Bao Wenjie and Selivanova Galina Rescue of p53 Function by Small-Molecule RITA in Cervical Carcinoma by Blocking E6Mediated Degradation Cancer Res April 15, 2010 70;3372.

Lane David P. Fang Cheok Chit and Lain Sonia p53-based Cancer Therapy Cold Spring Harb Perspect Biol 2010;2 originally published online May 12, 2010. 